\title{
Outcome of Bowel Resection in Women with Advanced Ovarian Carcinoma
}

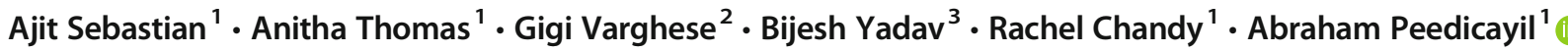

Received: 28 November 2017 / Accepted: 13 July 2018 / Published online: 20 July 2018

(C) Indian Association of Surgical Oncology 2018

\begin{abstract}
To evaluate the mortality and morbidity related to bowel resection in women with advanced ovarian carcinoma. Retrospective case series of 47 women with stage III and IV carcinoma ovary who underwent bowel resection, over the period of 5 years from Jan 2011 to Dec 2015. The risk factors for perioperative morbidity and death were determined by regression analysis. The disease free and overall survival were determined by Kaplan-Meier plots. In this cohort, 64\% (30/47) had primary debulking, 21\% (10/47) had interval debulking, and $15 \%$ (7/47) had secondary debulking. The mean period of follow-up was 23 months ( 1 to 45 months). There were no anastomotic leaks. The commonest morbidities were relaparotomy (8.5\%), surgical site infection (12\%), and paralytic ileus (19\%). The overall morbidity was $42.6 \%$ (20/47). The 30 -day mortality was $4.2 \%$ (2/47). The recurrence rate was $51 \%$ (20/47). The overall mortality from ovarian cancer in this cohort was $40 \%$ (19/47) during the follow-up period. Stage and histology seemed to be important risk factors for morbidity. Low BMI and sub-optimal debulking were significant risk factors for recurrence and death in univariate analysis. Bowel resection, in optimally selected cases of advanced carcinoma ovary, is often required for optimal cytoreduction. It carries a reasonable peri-operative mortality and morbidity and improves overall survival.
\end{abstract}

Keywords Ovarian cancer $\cdot$ Bowel resection

\section{Introduction}

Ovarian cancer (OC) is a systemic disease which is disseminated along peritoneal surfaces, frequently involving bowel and extending to the upper abdomen. Most patients (up to $70 \%$ ) will present with advanced stage disease $[1,2]$.

Primary debulking surgery followed by platinum and taxane-based chemotherapy is the current standard of treatment [3]. Despite advances in surgical techniques and systemic chemotherapy over the past three decades, ovarian cancer remains the leading cause of cancer death among women with gynecologic malignancies [4] with 5-year disease-free survival rates not exceeding 30\% [5].

Abraham Peedicayil

abraham@cmcvellore.ac.in

1 Department of Gynaecologic Oncology, CMC Hospital, Vellore 632004, India

2 Department of Colorectal Surgery, CMC Hospital, Vellore 632004, India

3 Department of Biostatistics, CMC Hospital, Vellore 632004, India
An increasing number of studies have shown that there is a significant improvement in survival with cytoreduction to microscopic residual disease (R0) compared to the current definition of "Optimal" cytoreductive surgery (R1 or residual $\leq 1 \mathrm{~cm}$ ) $[6-10]$.

In recent years, there is a trend to improve cytoreduction by maximal surgical effort that involves bowel resection and upper abdominal surgery. A few series of extended surgical procedures including abdominal and diaphragmatic peritonectomy, partial liver resection, and partial pancreatectomy or splenectomy have been published. The resections of parts of the digestive tract, especially the large bowel, are increasingly commonly performed [11-13].

Even though this type of surgery is usually performed in expert gynecologic oncology centers, it seems to be associated with a higher rate of intraoperative and early postoperative complications such as bleeding, anastomotic dehiscence, ICU admission, and infection. Diversion loop ileostomies might decrease the incidence and risks of bowel anastamosis. In selected patients, an end colostomy or an ileostomy becomes necessary, which inevitably leads to a significant deterioration of the comfort of living and quality of life. Many patients are not prepared to accept these risks. The advantages 
of optimal cytoreduction have to be balanced with the risks of extended surgery. It is now clear that if optimal primary cytoreduction is not achievable, then neoadjuvant chemotherapy is a better option.

The purposes of the study were to assess the immediate surgical outcomes after optimal cytoreduction with bowel resection and to find the risk factors of morbidity and mortality.

\section{Method}

After obtaining approval by the Institutional Review Board, all patients who underwent bowel resection during cytoreductive surgery for primary or recurrent OC (including fallopian tube and primary peritoneal cancer, collectively referred to as OC for this study) between January 1, 2011 and Dec 31, 2015 at our institute were identified. Electronic medical records including operative reports and discharge summaries were reviewed.

Patient-specific risk factors (including age, body mass index (BMI), CA 125 levels, preoperative albumin, preoperative hemoglobin), intraoperative risk factors (including type of bowel resection, number of resections, perioperative $\mathrm{RBC}$ transfusion, operative time, creation of diverting protective stomas at initial surgery), and outcomes (including anastomotic leak, surgical site infection, relaparotomy, paralytic ileus, 30-day mortality, overall survival) were abstracted. Patients were followed until death or last follow-up. Univariate and multivariate regression analyses were used to identify the prognostic factors for disease-free survival.

During the study period, we followed a uniform protocol for our ovarian cancer patients. The preferred management was primary cytoreductive surgery; however, neoadjuvant chemotherapy was given if there was carcinomatosis (massive ascites, extremely high CA 125 levels, or CT scan / laparoscopy showed optimal debulking to be unlikely) or if patient was above 65 years, frail, and a poor surgical candidate (ECOG > 2). All patients had a pre-operative CT scan and was discussed at a multidisciplinary team meeting. Interval debulking was done after 3 to 4 cycles of chemotherapy. Secondary debulking was undertaken if patient's performance status was good, ascites was absent, and, disease was localized and amenable for complete resection. Bowel resection was undertaken only if optimal debulking could be achieved.

\section{Results}

During the study period, there were 440 cases of ovarian cancer operated among which bowel resection was done in 47 $(10.6 \%)$. In this study cohort, 64\% (30/47) had primary debulking, $21 \%$ (10/47) had interval debulking, and 15\% (7/ 47 ) had secondary debulking. There were 16 patients who had stage IV disease and 31 patients who had stage IIIC disease. The commonest histology was epithelial 91\% (43/47) while non-epithelial was $9 \%$ (4/47). The median CA125 level was 300 (range 3 to 9010). The baseline patient and tumor characteristics are given in Table 1.

Optimal cytoreduction, defined as less than $1.0 \mathrm{~cm}$ residual disease, was achieved in 35 patients (75\%). Twelve patients (25\%) had suboptimal cytoreduction. The age, hemoglobin levels, BMI, and serum albumin levels were similar in both these groups. Mean blood loss during surgery was $1575 \mathrm{ml}$ (range 400 to 4500 ). The mean duration of surgery was $4.9 \mathrm{~h}$ (range 3 to $7 \mathrm{~h}$ ). Operative details are provided in Table 2. Most patients had extensive and complex surgery that included diaphragm stripping/resection, splenectomy, and peritonectomy in addition to the bowel resection.

Rectosigmoid resection was the most common type of bowel resection $(n=34)$. Hemicolectomy was performed in three patients, and sigmoid colectomy was also performed in three patients. One patient had total colectomy. Seven cases had small bowel resection (either ileum or jejunum). Eight patients had multiple bowel resections.

In 31 cases, the colon was re-anastomosed using the endto-end or side-to-side anastomosis. Sixteen patients had either an ileostomy or colostomy. About half of the patients had stapled anastomosis which was reinforced with sutures. Deep drains were placed for most patients and removed on return of bowel function.

Four $(8.5 \%)$ patients had re-laparotomy, 9 (19.1\%) patients had post-op ileus, and $6(12.8 \%)$ patients had surgical site infection. No patient had anastomotic leak in our series although it was suspected in two. The 30-day mortality was $2(4.3 \%)$; the first patient died of a myocardial infarction and a massive GI bleed (she had been started on heparin) and the other due to sepsis. The patient outcomes (complications, recurrence, and death) are shown in Table 3. In univariate analysis, only stage of disease was a significant risk factor for 30-day morbidity and mortality as shown in Table 4. In multivariate analysis, stage was a significant factor; however, the direction of risk had reversed. It appeared that stage III disease carried more morbidity as compared to stage IV probably because surgery was less aggressive in the latter. Epithelial ovarian cancer had twice the morbidity of non-epithelial cancer. Confidence limits could not be calculated due to small numbers.

The median follow-up time was 30 months (range 3 to 74 and interquartile range 16 to 51). Most patients had 6 cycles of chemotherapy with carboplatin and paclitaxel. Five patients did not take their chemotherapy at our center. Among those who recurred, second and third line chemotherapy were given, the maximum being a total of 24 cycles. Salvage chemotherapy consisted of liposomal doxorubicin and carboplatin with either gemcitabine or topotecan. Some patients were given bevacizumab, temozolomide, or tamoxifen. One patient had 
Table 1 Baseline characteristics

\begin{tabular}{ll}
\hline Factor & $N=47$ \\
\hline Age (mean, SD in years) & $47.0(8.7)$ \\
Hemoglobin (mean, SD in g/dl) & $10.8(1.2)$ \\
BMI (mean, SD in kg/m²) & $23.8(4.9)$ \\
Albumin (mean, SD in g/dl) & $3.9(0.6)$ \\
CA 125 in epithelial tumors $(\%)$ & \\
$<500$ & $27(63)$ \\
500 to 1000 & $4(9)$ \\
$>1000$ & $12(28)$ \\
Histology (\%) & \\
Serous & $26(55)$ \\
Mucinous & $9(19)$ \\
Endometrioid & $8(17)$ \\
Non-epithelial & $4(9)$ \\
Stage of disease $(\%)$ & \\
III & $31(66)$ \\
IV & $16(34)$ \\
\hline
\end{tabular}

radiation and one had secondary cytoreduction with hyperthermic intraperitoneal chemotherapy (SCRS + HIPEC) at recurrence. Radiation was given for localized recurrence that persisted after second-line chemotherapy.

At the end of this study, the overall mortality was 19 (40.0\%). Among those who had suboptimal cytoreduction, $50 \%$ died (6/12) whereas after optimal cytoreduction, $37 \%$ $(13 / 35)$ had died. Thirty-one patients were still alive at the end of 5 years and 20 patients had recurrence for which they got either second-line or re-challenge chemotherapy. The overall survival and progression-free survival curves are given in Figs. 1 and 2. The median time to recurrence was 35 months and median overall survival time was 53 months. The

Table 2 Operative details $(n=47)$

\begin{tabular}{ll}
\hline Factor & Number (\%) \\
\hline $\begin{array}{l}\text { Type of surgery } \\
\text { Primary }\end{array}$ & $30(64)$ \\
Interval & $10(21)$ \\
Secondary & $7(15)$ \\
Bowel resection & \\
Small & $7(15)$ \\
Large & $34(72)$ \\
Small and large & $6(13)$ \\
Stoma & $16(34)$ \\
Diaphragm stripping & $15(32)$ \\
Splenectomy & $6(13)$ \\
Peritonectomy & $22(47)$ \\
Optimal debulking & $35(75)$ \\
\hline
\end{tabular}

Table 3 Outcomes after surgery $(n=47)$

\begin{tabular}{lll}
\hline Paralytic ileus & 9 & $19.1 \%$ \\
Surgical site infection & 6 & $12.8 \%$ \\
Relaparotomy & 4 & $8.5 \%$ \\
Recurrence & 24 & $51.1 \%$ \\
Death & 19 & $40.4 \%$ \\
\hline
\end{tabular}

recurrence-free survival and overall survival by stage of disease are given in Figs. 3 and 4. The recurrence-free survival and overall survival by residual disease are given in Figs. 5 and 6 .

\section{Discussion}

Cytoreductive surgeries performed in patients with advancedstage ovarian cancer are among the most challenging in gynecologic oncology. Since the publication by Griffiths showing that survival is improved if the diameter of residual tumor implants after debulking does not exceed $15 \mathrm{~mm}$, achieving optimal cytoreduction became the main goal of surgery [14]. In fact, the only modifiable risk factor is the extent of surgery and the amount of residual disease. In addition to surgery, adjuvant or neoadjuvant chemotherapy with platinum and paclitaxel is the main stay of treatment [15]. The goal of surgery is to obtain zero macroscopic residual tumor or complete (R0) cytoreduction [16-18]. Residual tumor deposits less than $10 \mathrm{~mm}$ at the end of surgery is still considered optimal [19]. This strategy of maximal surgical effort sometimes requires multi-organ resections adding to the complexity of surgery. Most commonly, parts of the digestive tract are resected, especially the large bowel.

In 2003, Bristow and co-workers published the results of surgery in 31 patients with stage IIIB and IV disease in whom rectosigmoid resection with stapler anastomosis was performed [20]. The radical cytoreduction defined as no tumor residues larger than $10 \mathrm{~mm}$ was achieved in $87 \%$ of patients. There was no peri-operative mortality, and the average blood loss was $700 \mathrm{ml}$. Anastomotic dehiscence occurred in one patient. The overall rate of large bowel (dehiscence, bleeding) and small bowel (fever, wound infection, pneumonia) complications was 12.9

Table 4 Risk factors for operative morbidity

\begin{tabular}{lll}
\hline Factor & $\begin{array}{l}\text { Univariate } \\
\text { OR 95\% CI }\end{array}$ & $\begin{array}{l}\text { Multivariate } \\
\text { OR 95\% CI }\end{array}$ \\
\hline Age & $1.06(0.98-1.14)$ & $1.06(0.93-1.21)$ \\
BMI & $0.95(0.83-1.08)$ & $0.91(0.77-1.08)$ \\
Albumin & $1.02(0.37-2.84)$ & $1.53(0.27-8.81)$ \\
Residual disease & $3.71(0.69-20.04)$ & $0.28(0.04-1.96)$ \\
Stage (III vs IV) & $0.27(0.08-0.97)$ & $8.17(1.29-51.79)$ \\
Stoma & $0.46(0.12-1.76)$ & $0.28(0.04-2.04)$ \\
\hline
\end{tabular}




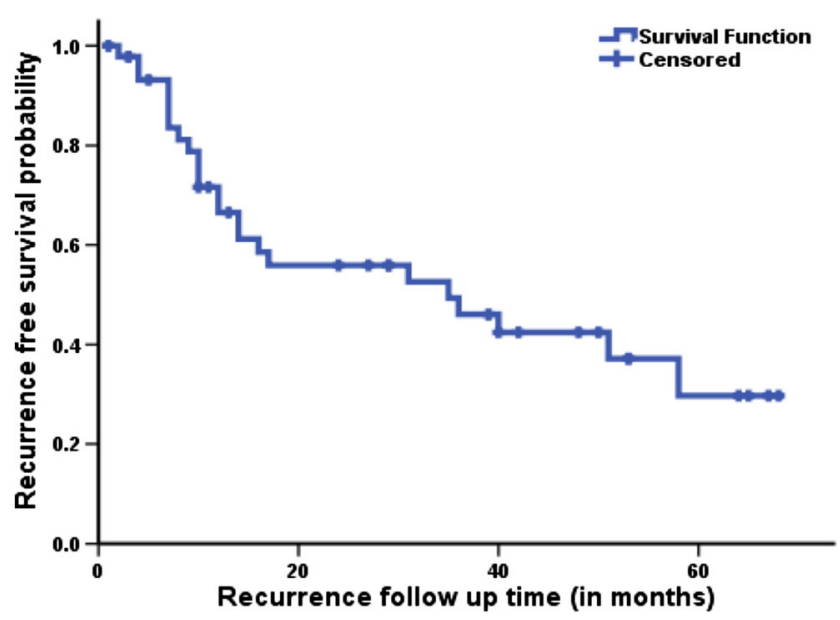

Fig. 1 Progression-free survival

and $35.5 \%$, respectively. Obermair and co-workers reported 65 cytoreductive surgeries with rectosigmoid resection and end-to-end anastomosis [21]. Optimal cytoreduction was achieved in 48 patients $(73.8 \%)$. Complications included the following: one bowel fistula (1.5\%), two cases of anastomotic dehiscence (3.1\%), two cases of ileus $(3.1 \%), 14$ cases of wound infection $(21.5 \%)$, and five thromboembolic complications $(7.7 \%)$. One patient died immediately after the surgery and three patients were reoperated [21]. Chia et al. reported on the results of surgery in 38 patients with advanced-stage ovarian cancer [22]. The most often performed operative procedure in this group of patients was resection of the sigmoid and rectum $(76.3 \%)$. Colostomy was performed in $61 \%$ of patients. Optimal cytoreduction was achieved in $71 \%$ of patients. Perioperative complications included one anastomotic dehiscence $(2.6 \%)$, one enteric fistula $(2.6 \%)$, and two inter-loop abscesses (5.3\%). Reoperation was required in three patients. During 30 days after the surgery, three patients died [22]. All aforementioned authors were

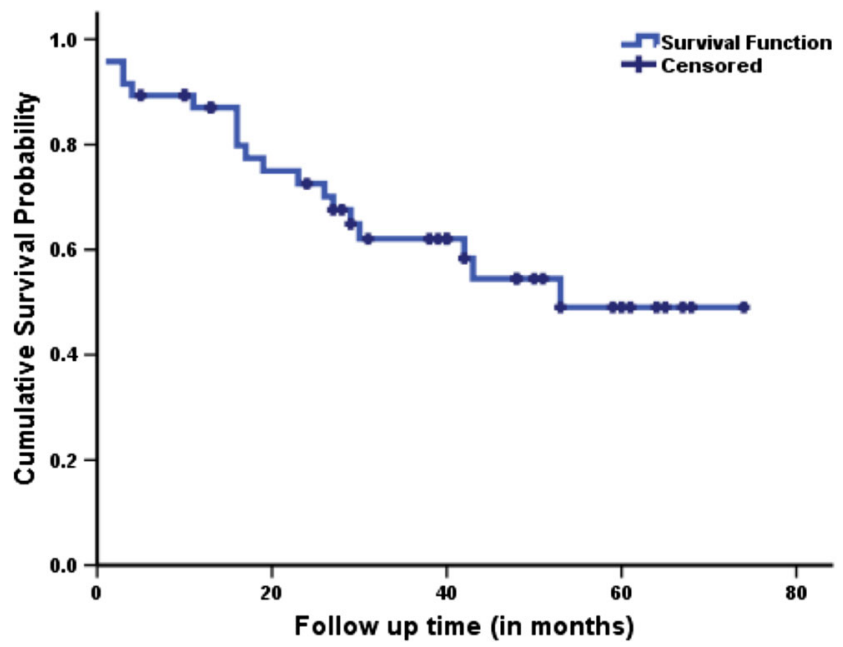

Fig. 2 Overall survival unanimous that cytoreduction with bowel resection, most often of the sigmoid and rectum, gives good results and the rate of perioperative complications is acceptable. In 2007, Bidzinski et al. published their experience in performing rectosigmoid resection or colectomy in patients with FIGO stage III and IV ovarian cancer [13]. This series from 2007 consisted of 39 patients treated in a single center. They were able to achieve a radical cytoreduction (macroscopic implants $<10 \mathrm{~mm}$ ) in $32 \mathrm{pa}-$ tients $(82 \%)$. There were three $(7.6 \%)$ cases of anastomotic dehiscence, and one patient developed intestinal obstruction $(2.5 \%)$. The average blood loss was $1120 \mathrm{ml}$, and the average surgery time was $175 \mathrm{~min}$. There were no perioperative deaths. Colostomy was performed in $36.4 \%$ of 39 patients. In 2012, Peiretti and co-workers published the results of the multicenter study which was conducted between 1998 and 2008 that included 238 patients with carcinoma of the ovary, fallopian tube, and peritoneum where rectosigmoid resection was performed as a part of cytoreductive surgery [23]. Stapled anastomosis was performed in $98 \%$ of patients. Ileostomy was performed in two $(0.8 \%)$ and colostomy in five $(2 \%)$ of the patients. Complete cytoreduction was achieved in $41 \%$ of the patients. Anastomotic dehiscence occurred in nine patients (3\%) [23]. Anastomotic dehiscence is one of the most serious complications related to bowel surgery, especially in rectosigmoid resection with low anastomosis. The incidence of this complication is between 2.8 and $23 \%$ for resections of colonic cancer and between 0.8 and $6.8 \%$ for gynecologic cancers $[20,21,24,25]$. A higher rate of complications after non-gynecologic surgeries may be due to pre-operative radiation for rectal cancers. The mortality from anastomotic leaks ranges from 7.3 to $16 \%$, and approximately one third of deaths related to colorectal surgery is due to this complication [26, 27]. Our rate of optimal debulking, stoma rate, and perioperative morbidity and mortality are comparable to other reports on cytoreductive surgery for ovarian cancer.

The factors contributing to a higher risk of anastomotic dehiscence include protracted surgery, blood transfusion, and short distal segment of anastomosis. It was suggested that diverting ileostomy or colostomy might protect against this complication. On the other hand, overall rate of complications associated with en-bloc resection of the uterus and adnexa with tumor-infiltrated rectosigmoid without protective ileostomy is low, around 2\% [28]. Therefore, ileostomy should not be performed on a routine basis but only in specific situations such as poor nutrition, significant ascites, anastomosis under tension or multiple anastomoses [29]. Similarly, Hartmann's procedure should be reserved only for patients with significant comorbidities or as a "salvage procedure" [30].

Thorough preoperative work up is a prerequisite of optimal cytoreduction. Well-selected imaging studies may help to 
Fig. 3 Overall survival by stage of disease

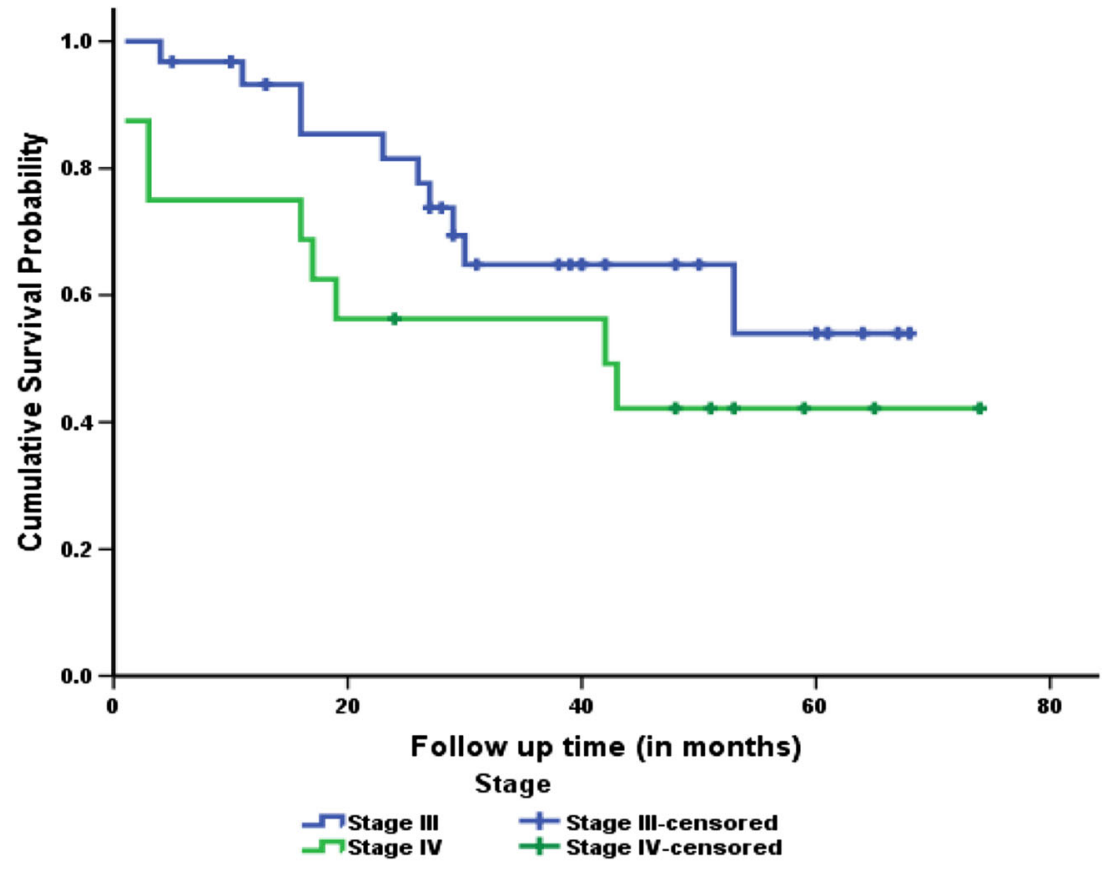

avoid unnecessary surgery in patients with large unresectable foci of tumor. Multidetector computer tomography (MDCT) has established itself as an excellent tool for preoperative assessment of patients with ovarian cancer. The recent papers confirm high agreement of MDCT with both intraoperative and pathologic assessment of resectability and clinical grading of ovarian cancer [31]. Magnetic resonance imaging with diffusion-weighted imaging is very efficient in demonstrating the infiltration of adjacent organs and small peritoneal implants $[32,33]$. Several papers have addressed the issue of influence of extended surgery on survival. One of the first papers was published by Scarabelli and coworkers [35].
Two-year survival reached $100 \%$ for patients without macroscopic tumor after surgery and $77 \%$ for patients with foci of $1 \mathrm{~cm}$ diameter. None of the patients with residual disease larger than $2 \mathrm{~cm}$ had survived 2 years [34]. According to the results of Takahashi and co-workers, the 5-year cumulative survival rate was $60.8 \%$ in patients without residual disease and $0 \%$ in patients with macroscopic disease [35]. It was observed that cumulative 5-year survival in patients undergoing primary radical cytoreductive surgery with bowel resection was $62.2 \%$, while that in patients operated after neoadjuvant chemotherapy, survival was only $13.9 \%$ [35]. Arora analyzed a group of 203 women with FIGO stage IIIC and IV ovarian
Fig. 4 Recurrence-free survival by stage of disease

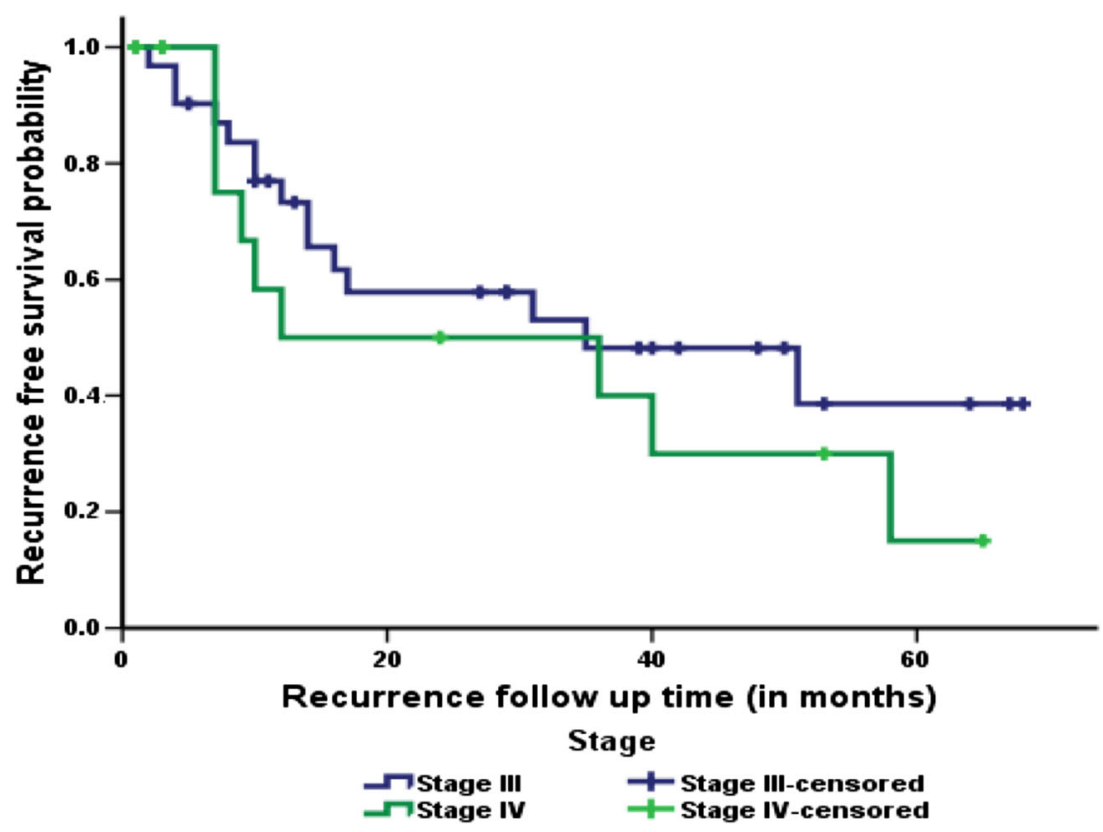


Fig. 5 Overall survival by debulking achieved

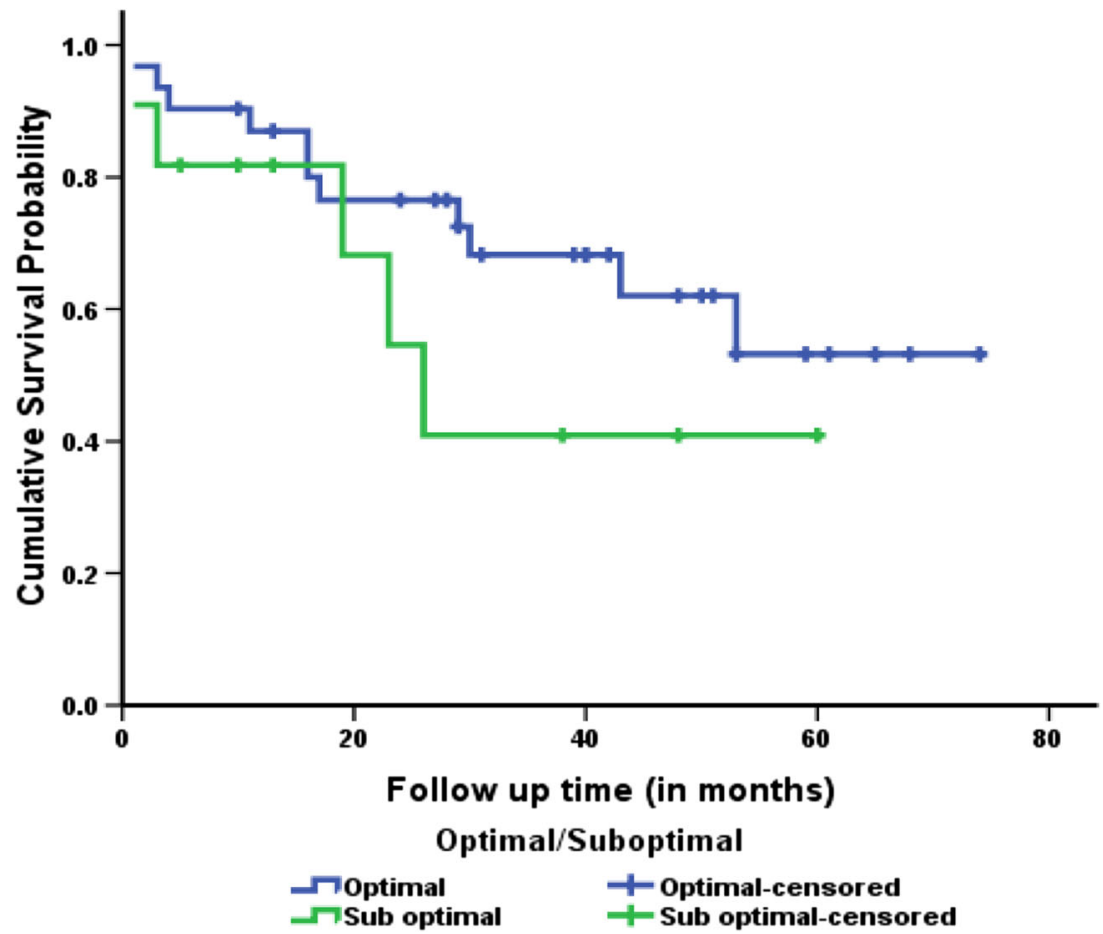

cancer operated during a 10-year period [36]. In 51 patients from this group, optimal cytoreduction was achieved with bowel resection. The median follow-up time was 84 months (range 28-159 months). Two-year disease-free survival was reached by $63 \%$ of patients. Priretti et al. showed that recurrence occurred in $50 \%$ of 238 patients [23]. However, only $5 \%$ of them showed a relapse at the level of the pelvis whereas $8 \%$ presented with abdominal recurrence associated with pelvic disease as well. The median overall survival time among patients with complete cytoreduction was 72 months compared with 42 months among the rest of the patients $(P=0.002)$ [23]. In the present study, we achieved optimal cytoreduction in $75 \%$ of patients with a third of patients having a stoma. There were no anastomotic leaks although we did lose two patients within 30 days. The 5-year overall survival was $66 \%$ which is comparable to other reports on cytoreductive surgery for ovarian cancer where optimal debulking is achieved.

In our series, patients were carefully selected for bowel resection. All patients had pre-operative CT imaging. Although we included stage IV disease, survival outcome was good as we
Fig. 6 Recurrence-free survival by debulking achieved

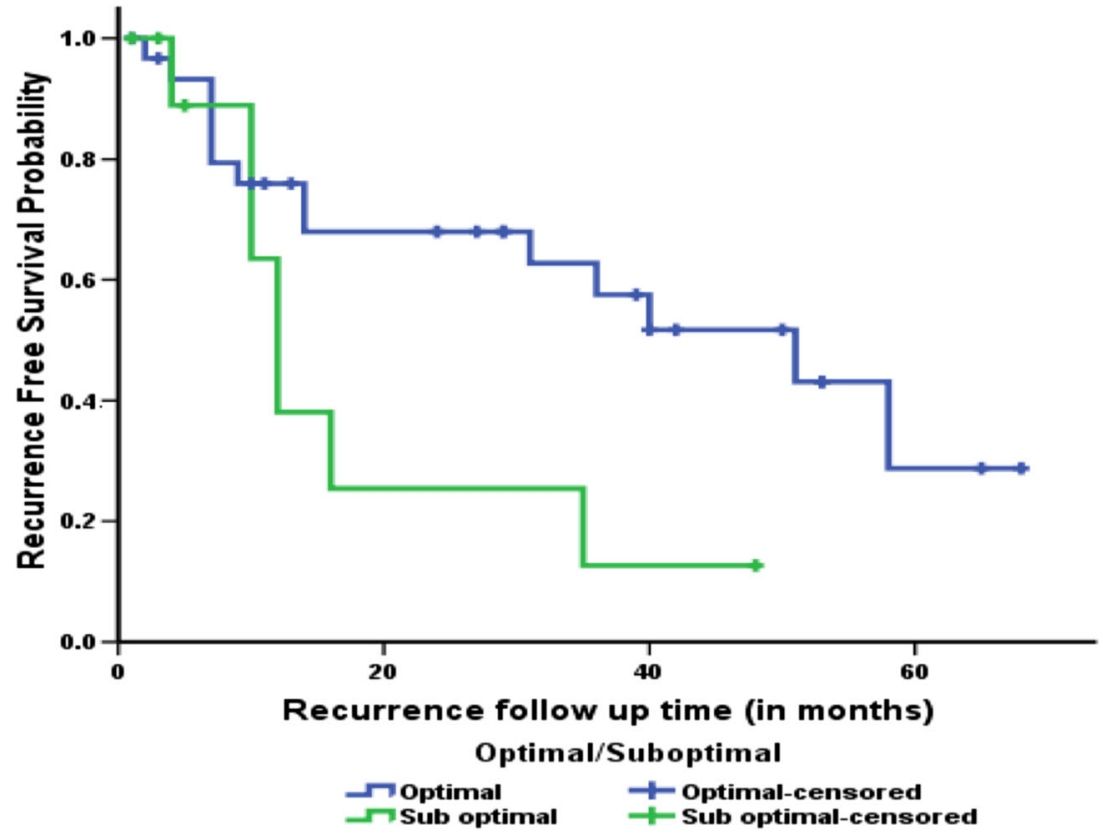


were able to achieve optimal debulking by excising inguinal nodes and umbilical nodules. Our neoadjuvant chemotherapy rate was $40 \%$ during the period of this study and only those who responded at least partially to chemotherapy would have had bowel resection. Our low morbidity rates could be attributed to careful selection of cases, liberal use of a diverting stoma, and good intra-operative and post-operative care.

All our patients were managed by a dedicated medical oncologist after surgery and would have had at least 6 monthly CA 125 estimations and annual imaging. Recurrences were managed by rechallenging with carboplatin and paclitaxel or second-line chemotherapy. Those who were amenable to secondary cytoreduction were offered a second surgery. The relatively good survival data for our patients pertains not to all those with stage IIIC and IV but only those who underwent bowel resection. There would be a degree of selection bias as the most severe cases where optimal debulking was unlikely were excluded. The majority of our patients had optimal cytoreduction. Many of our patients had multiple lines of chemotherapy and other salvage treatments. The median followup time was 30 months as many died before this or were lost to follow-up. With a longer period of follow-up, more recurrences and deaths could be expected.

Several studies have shown that the amount of residual disease is an important determinant of survival [37, 38]. Although biology of the tumor is very important, the only modifiable risk factor for recurrence and cancer-related death is the amount of residual disease. Women in whom residual disease is zero can have long-term survival with good quality of life, even after extensive abdominal surgery. It remains to be proved whether hyperthermic intraperitoneal chemotherapy (HIPEC) can increase overall survival without increasing the perioperative morbidity and mortality. Since there are more chemotherapeutic options now, post-progression survival is a better correlate of overall survival than progression-free survival [39].

\section{Conclusions}

Bowel resection enables optimal cytoreduction in patients with advanced ovarian cancer and thereby improves overall survival. The perioperative morbidity and mortality can be minimized by careful patient selection, operative techniques such as diverting stomas, and attention to post-operative care.

\section{References}

1. Heintz AP, Odicino F, Maisonneuve P, Beller U, Benedet JL, Creasman WT et al (2003) Carcinoma of the ovary. Int J Gynecol Obstet 83(Suppl 1):135-166
2. Pecorelli S, Favalli G, Zigliani L, Odicino F (2003) Cancer in women. Int J Gynecol Obstet 82:369-379

3. Ozols RF, Bundy BN, Greer BE, Fowler JM, Clarke-Pearson D, Burger RA, Mannel RS, DeGeest K, Hartenbach EM, Baergen R, Gynecologic Oncology Group (2003) Phase III trial of carboplatin and paclitaxel compared with cisplatin and paclitaxel in patients with optimally resected stage III ovarian cancer: a gynecologic oncology group study. J Clin Oncol 21:3194-3200

4. Siegel R, Ward E, Brawley O, Jemal A (2011) Cancer statistics, 2011: the impact of eliminating socioeconomic and racial disparities on premature cancer deaths. CA Cancer J Clin 61:212-236

5. Armstrong DK, Bundy B, Wenzel L, Huang HQ, Baergen R, Lele S, Copeland LJ, Walker JL, Burger RA, Gynecologic Oncology Group (2006) Intraperitoneal cisplatin and paclitaxel in ovarian cancer. N Engl J Med 354:34-43

6. Bristow RE, Montz FJ (2001) Complete surgical cytoreduction of advanced ovarian carcinoma using the argon beam coagulator. Gynecol Oncol 83:39-48

7. Eisenkop SM, Friedman RL, Wang HJ (1998) Complete cytoreductive surgery is feasible and maximizessurvival in patients with advanced epithelial ovarian cancer: a prospective study. Gynecol Oncol 69:103-108

8. Eisenkop SM, Spirtos NM, Friedman RL, Lin WC, Pisani AL, Perticucci S (2003) Relative influences of tumor volume before surgery and the cytoreductive outcome on survival for patients with advanced ovarian cancer: a prospective study. Gynecol Oncol 90:390-396

9. Le T, Krepart GV, Lotocki RJ, Heywood MS (1997) Does debulking surgery improve survival in biologically aggressive ovarian carcinoma? Gynecol Oncol 67:208-214

10. Makar AP, Baekelandt M, Trope CG, Kristensen GB (1995) The prognostic significance of residual disease, FIGO substage, tumor histology, and grade in patients with FIGO stage III ovarian cancer. Gynecol Oncol 56:175-180

11. Salani R, Zahurak ML, Santillan A, Giuntoli RL 2nd, Bristow RE (2007) Survivalimpact of multiple bowel resections in patients undergoing primarycytoreductive surgery for advanced ovarian cancer: a case-control study. Gynecol Oncol. 107:495-499

12. Estes JM, Leath CA 3rd, Straughn JM Jr, Rocconi RP, Kirby TO, Huh WK et al (2006) Bowel resection at the time of primary debulking for epithelial ovariancarcinoma: outcomes in patients treated with platinum and taxane-basedchemotherapy. J Am Coll Surg 203:527-532

13. Bidzinski M, Derlatka P, Kubik P, Ziolkowska-Seta I, DańskaBidzinska A, Gmyrek L et al (2007) The evaluation of intra- and postoperative complicationsrelated to debulking surgery with bowel resection in patients with FIGOstage III-IV ovarian cancer. Int J Gynecol Cancer 17:993-997

14. Griffiths CT (1975) Surgical resection of tumor bulk in the primary treatment of ovarian carcinoma. Natl Cancer Inst Monogr 42:101-104

15. Bristow RE, Tomacruz RS, Armstrong DK, Trimble EL, Montz FJ (2002) Survival effect of maximal cytoreductive surgery for advanced ovarian carcinoma during the platinum era: a meta-analysis. J Clin Oncol 20:1248-1259

16. Wimberger P, Lehmann N, Kimmig R, Burges A, Meier W, Du Bois A (2007) Prognostic factors for complete debulking in advanced ovarian cancer and its impact on survival. An exploratory analysis of a prospectively randomized phase III study of the Arbeitsgemeinschaft Gynaekologische Onkologie ovarian Cancer study group (AGO-OVAR). Gynecol Oncol 106:69-74

17. Eisenhauer EL, Abu-Rustum NR, Sonoda Y, Aghajanian C, Barakat RR, Chi DS (2008) The effect of maximal surgical cytoreduction on sensitivity to platinum-taxane chemotherapy and subsequent survival in patients with advanced ovarian cancer. Gynecol Oncol 108:276-281 
18. Eisenkop SM, Spirtos NM, Lin WC (2006) "Optimal" cytoreduction for advanced epithelial ovarian cancer: a commentary. Gynecol Oncol 103:329-335

19. Chi DS, Eisenhauer EL, Lang J, Huh J, Haddad L, AbuRustum NR, Sonoda Y, Levine DA, Hensley M, Barakat RR (2006) What is the optimal goal of primary cytoreductive surgery for bulky stage IIIC epithelial ovarian carcinoma (EOC)? Gynecol Oncol 103:559-564

20. Bristow RE, Del Carmen MG, Kaufman HS, Montz FJ (2003) Radical oophorectomy with primary stapled colorectal anastomosis for resection of locally advanced epithelial ovarian cancer. J Am Coll Surg 197:565-574

21. Obermair A, Hagenauer S, Tamandl D, Clayton RD, Nicklin JL, Perrin LC, Ward BG, Crandon AJ (2001) Safety and efficacy of low anterior en bloc resection as part of cytoreductive surgery for patients with ovarian cancer. Gynecol Oncol 83:115-120

22. Chia YN, Tay EH, Cheong DM, Eu KW, Low J, Ho TH et al (2003) Bowel surgery for epithelial ovarian cancer - an early case series. Ann Acad Med Singap 32:661-664

23. Peiretti M, Bristow RE, Zapardiel I, Gerardi M, Zanagnolo V, Biffi R, Landoni F, Bocciolone L, Aletti GD, Maggioni A (2012) Rectosigmoid resection at the time of primary cytoreduction for advanced ovarian cancer. A multi-center analysis of surgical and oncological outcomes. Gynecol Oncol 126:220-223

24. Peeters KC, Tollenaar RA, Marijnen CA, Klein Kranenbarg E, Steup WH, Wiggers $\mathrm{T}$ et al (2005) Risk factors for anastomotic failure after total mesorectal excision of rectal cancer. Br J Surg 92:211-216

25. Yeh CY, Changchien CR, Wang JY, Chen JS, Chen HH, Chiang JM, Tang R (2005) Pelvic drainage and other risk factors for leakage after elective anterior resection in rectal cancer patients: a prospective study of 978 patients. Ann Surg 241:9-13

26. McArdle CS, McMillan DC, Hole DJ (2005) Impact of anastomotic leakage on long-term survival of patients undergoing curative resection for colorectal cancer. Br J Surg 92:1150-1154

27. Wong NY, Eu KW (2005) A defunctioning ileostomy does not prevent clinical anastomotic leak after a low anterior resection: a prospective, comparative study. Dis Colon Rectum 48:2076-2079

28. Mourton SM, Temple LK, Abu-Rustum NR, Gemignani ML, Sonoda Y, Bochner BH et al (2005) Morbidity of rectosigmoid resection and primary anastomosis in patients undergoing primary cytoreductive surgery for advanced epithelial ovarian cancer. Gynecol Oncol 99:608-614
29. Kalogera E, Dowdy SC, Mariani A, Weaver AL, Aletti G, Bakkum-Gamez JN, Cliby WA (2013) Multiple large bowel resections: potential risk factor for anastomotic leak. Gynecol Oncol 130:213-218

30. Seah DW, Ibrahim S, Tay KH (2005) Hartmann procedure: is it still relevant today? ANZ J Surg 75:436-440

31. Kyriazi S, Kaye SB, DeSouza NM (2010) Imaging ovarian cancer and peritoneal metastases - current and emerging techniques. Nat Rev Clin Oncol 7:381-393

32. Michielsen K, Vergote I, Op de Beeck K, Amant F, Leunen K, Moerman P et al (2014) Whole-body MRI with diffusionweighted sequence for staging of patients with suspected ovarian cancer: a clinical feasibility study in comparison to CT and FDGPET/CT. Eur Radiol 24:889-901

33. Levy A, Medjhoul A, Caramella C, Zareski E, Berges O, Chargari C, Boulet B, Bidault F, Dromain C, Balleyguier C (2011) Interest of diffusion-weighted echo-planar MR imaging and apparent diffusion coefficient mapping in gynecological malignancies: a review. $\mathrm{J}$ Magn Reson Imaging 33:1020-1027

34. Scarabelli C, Gallo A, Franceschi S, Campagnutta E, De G, Giorda $\mathrm{G}$ et al (2000) Primary cytoreductive surgery with rectosigmoid colon resection for patients with advanced epithelial ovarian carcinoma. Cancer 8:389-397

35. Takahashi O, Sato N, Miura Y, Ogawa M, Fujimoto T, Tanaka H, Sato H, Tanaka T (2005) Surgical indications for combined partial rectosigmoidectomy in ovarian cancer. J Obstet Gynaecol Res 31: 556-561

36. Arora M, Saha S, Puthillath A, Sehgal R, Dutt N, Metz J, Misra A, Perez M, Wiese D, Singh T (2005) Impact of radical bowel resection on survival in advanced epithelial ovarian cancer. J Clin Oncol 23:5166

37. Hamilton CA, Miller A, Miller C, Krivak TC, Farley JH, Chernofsky MR et al (2011) The impact of disease distribution on survival in patients with stage 3 epithelial ovarian cancer cytoreduced to microscopic residual: A gynecologic oncology group study. Gynecol Oncol 122:521-526

38. Fagotti A, Gallotta V, Romano F, Fanfani F, Rossitto C, Naldini A et al (2010) Peritoneal carcinosi of ovarian origin. World J Gastrointest Oncol 15:102-108

39. Shimokawa M, Kogawa T, Shimada T, Saito T, Kumagai H, Ohki M, Kaku T (2018) Overall survival and post-progression survival are potent end point in phase III trials of second/third line chemotherapy for advanced or recurrent epithelial ovarian cancer. J Cancer 9:872-879 